\title{
Adana-Feke Yöresi Yeraltı Çinko Cevherleşmesinin Asit Maden Drenajı Oluşumuna Yönelik Kestirimlerinin Araştırılması
}

\author{
Nil YAPICI ${ }^{* 1}$, Hakan GÜNEYLí2 \\ ${ }^{1}$ Çukurova Üniversitesi, Mühendislik Fakültesi, Maden Mühendisliği Bölümü, Adana \\ ${ }^{2}$ Çukurova Üniversitesi, Mühendislik Fakültesi, Jeoloji Mühendisliği Bölümü, Adana
}

Geliş tarihi: 24.03 .2021

Kabul tarihi: 30.06 .2021

\section{$\ddot{\mathbf{O z}}$}

Bu çalışma, Adana ili, Feke ilçesi sınırlarında 1/25.000 ölçekli Kozan M35b4 paftası içinde bulunan "Kapalı İşletme Cevher Maden Ocağı (Çinko cevherleşmesi)" faaliyetlerinden kaynaklanabilecek asit maden drenaj sorununu ele almaktadır. Saha ve laboratuvar çalışmaları sonucunda; mineral parajenezleri, kimyasal analizler, Çamur pH deneyleri, Asit-Baz Hesabı $(\mathrm{ABH})$ yorum parametreleri olan Asit Üretme Potansiyeli (AÜP), Nötürleştirme Potansiyeli (NP), Net Nötürleşme Potansiyeli (NetNP) ve Nötürleşme Potansiyel oranları (NPO) hesaplanarak Asit Baz Muhasebesi (ABM) yapılmıştır. Cevherleşme, faylanmalara bağlı olarak Orta-Üst Kambriyen yaşlı Değirmentaş formasyonuna ait karbonatlı kayaçlar içerisinde yarı düzenli geometrik formda gözlenmiştir. Cevher mineral parajenezleri; hidrozinkit $\left(\mathrm{Zn}_{5}\left(\mathrm{CO}_{3}\right)_{2}(\mathrm{OH})_{6}\right)$, zinkit $(\mathrm{ZnO})$, smitsonit $\left(\mathrm{ZnCO}_{3}\right)$ hematit $\left(\mathrm{Fe}_{2} \mathrm{O}_{3}\right)$, götit $\left(\mathrm{HFeO}_{2}-\mathrm{FeO}(\mathrm{OH})\right)$, limonit $\left(\mathrm{FeO}(\mathrm{OH}) \cdot \mathrm{nH}_{2} \mathrm{O}\right)$ ve az oranda pirit $\left(\mathrm{FeS}_{2}\right)$ minerallerinden oluşmaktadır. Kayaç içerisinde kükürt değerleri $(\% \mathrm{~S})$ 0,04-0,12, cevherde kükürt değerleri ise \%0,13-0,39 aralığında tespit edilmiştir. AÜP değeri kayaçta; 2,50-7,50, cevherde; 8,13-24,38 arasında bulunmuştur. NPO (Nötürleştirme Potansiyel Oranı) kayaçta; 64,05-188,92, cevherde; 4,37-14,27 aralığında saptanmıştır. Her ne kadar tüm değerler 'asit üretmez' şartını sağlamakta ise de cevher mekanizması gereği durum “kritik" olarak ele alınmalı ve ilgili yasa ve yönetmeliklere uyulmalıdır.

Anahtar kelimeler: Asit maden drenajı, Kestirim yöntemleri, Asit-baz hesabı, Çinko cevheri

\section{Investigation of Acid Rock/Mine Drainage During of Feke/Adana Zinc Ore Mining} Activities

\begin{abstract}
This study addresses the acid mine drainage problem that may cause from the activities of the "Underground Mine Ore Mine (Zinc mineralization)", located in the 1/25.000 scale Kozan M35b4 map in the borders of Adana province, Feke county. By carrying out field and laboratory studies; Acid-Base Accounting $(\mathrm{ABM})$ has been done through "Mineral paragenesis, chemical analyzes, Sludge pH tests, Acid-Base Calculation (ABH) interpretation parameters of Acid Generating Potential (AUP), Neutralization Potential (NP), Net Neutralization Potential (NetNP) and Neutralization Acid Base
\end{abstract}

*Sorumlu yazar (Corresponding author): Nil YAPICI, nyapici@cu.edu.tr 

Araştırılması

Accounting (ABM) by calculating potential rates (NPO)". Mineralization is in semi-regular geometric form within the carbonate rocks belonging to the Middle-Upper Cambrian aged Değirmentaş formation due to faulting. Ore mineral paragenesis consists of hydrozincite $\left(\mathrm{Zn} 5\left(\mathrm{CO}_{3}\right) 2(\mathrm{OH})_{6}\right)$, zincite $(\mathrm{ZnO})$, smithsonite $\left(\mathrm{ZnCO}_{3}\right)$ hematite $\left(\mathrm{Fe}_{2} \mathrm{O}_{3}\right)$, goethite $\left(\mathrm{HFeO}_{2}-\mathrm{FeO}(\mathrm{OH})\right)$, limonite $\left(\mathrm{FeO}(\mathrm{OH}) \mathrm{nH}_{2} \mathrm{O}\right)$ and a small amount of pyrite $\left(\mathrm{FeS}_{2}\right)$ minerals. Sulfur values $(\mathrm{S} \%)$ in the rock are in the range of $0.04-0.12 \%$, and in the ore are of $0.13-0.39 \%$. APP value range is $2.50-7.50$ in the rock; $8.13-24.38$, in the ore. NPR (Neutralization Potential Ratio) was determined in range of 64.05-188.92 in rock; 4.37-14.27 in the ore. Although all values meet the requirements, according to the statement "does not produce acid", due to ore mechanism the situation should be considered as "critical" and relevant laws and regulations must be followed.

Keywords: Acid mine drainage, Estimation methods, Acid-base calculation, Zinc ore

\section{GİRiş}

Başta pirit olmak üzere sülfürlü metalik mineraller madencilik faaliyetleri sirasında atmosferle temasın artması ve mikrobiyolojik organizmaların katkısı ile oksitlenerek bulundukları drenaj sularının asidik özellik kazanmalarına neden olmaktadır. $\mathrm{Bu}$ drenaj suları geçtikleri formasyonlar içerisindeki bazı ağır ve toksik elementleri çok kolay çözerek bünyesine katmaktadır. Bu çevresel olay asit maden drenajı (AMD) olarak tanımlanmaktadır [1-3]. Mikrobiyolojik organizmaların AMD üzerine etkisini, Balcı (2014)'de yaptığı çalışmada; $\mathrm{Pb} / \mathrm{Zn}$ atık sahasında $S$ ve $F$ döngüsünde etkili mikroorganizmaların asidik suların oluşumunda ve bileşiminde ana rol oynadıklarını ortaya çıkararak belirtmiştir [4].

Asit maden drenajı özellikle nehir ve göllerin ekosistemleri üzerinde etkilidir. Sonuçta bitki ve hayvan türlerini elimine edip besin zincirinin basitleşmesine, hatta yıkılmasına neden olabilir ve sudaki yaşamı tamamen ortadan kaldırabilir [5].

AMD oluşumunda fiziksel faktörler önemli rol oynamaktadır. Bunlardan en önemlileri madenin bulunduğu ilk konumdaki durumu, yankayaç bileşimi, faylanmalar ve süreksizlikler, tabakalar arası boşluklar ve geçirgenlik gibi özelliklerdir. Ekosistemin bozulmaması ve canlı yaşamının rehabilitesi için AMD'nın doğru jeokimyasal modellerle yönetilmesi gerekmektedir.

Son yıllarda olası asit maden drenajının gelişmesini önlemek amacıyla maden sahasının etrafında drenaj kanalları açılması ve kireçtaşı dolgusu uygulamaları, kullanılan en yaygın yöntemleri oluşturmaktadır [6-15]. AMD oluşum kestiriminde Miller (1996), Morin ve Hutt (1997), White ve arkadaşları (1999), Paktunç (1999), Jambor ve arkadaşları (2000), Jambor ve arkadaşları. (2002) ve Weber ve arkadaşları. (2006) statik testlerin hızlı bir yöntem olduğunu ve geliştirilmesi yönünde fikir sunmuşlardır [16-22].

$\mathrm{Bu}$ çalışmanın amacı, M35-b4 paftası içinde Kozan-Feke-Mansurlu yaylası arasında yer alan çinko cevherleşmesinde olası AMD oluşumunun araştırılmasıdır. Çalışma konusu olan çinko cevherleşmesi Adana İl merkezine kuş uçuşu 90 $\mathrm{km}$ Feke İlçe'sine ise $5 \mathrm{~km}$ mesafede bulunmaktadır. Söz konusu maden, yeraltı işletmesi olarak çalıştırılmaktadır. Bölgede çinko cevherinin oluşturabileceği asit üretme potansiyeli araştırılmamıştır.

Feke bölgesinde maden ruhsatlı birçok $\mathrm{Pb}-\mathrm{Zn}, \mathrm{Fe}$, $\mathrm{Al}, \mathrm{Mn}, \mathrm{Cu}, \mathrm{Au}, \mathrm{Ag}$ ve $\mathrm{Ba}$ zenginleşmelerine ait maden yatakları bulunmaktadır. Bölge jeolojisi ve tektonik özellikleri ile oldukça karmaşık bir yap1 sunar. Bölgedeki cevher yerleşimini tektonik yapı belirlemektedir. Bölgesel cevher mekanizmaları başlica hidrotermal, hidrotermal-sedimanter, stratabound ve karstik olarak sıralanabilir.

\subsection{Bölgesel Jeoloji}

Torosların batı kesiminde yer alan çalışma alanı ve yakın çevresi farklı stratigrafi özellikleri ile kapsadıkları kayaç türleri bakımından çeşitli oluşum tiplerini belirleyen ve birbirleriyle tektonik 
dokanaklı değişik tektono-stratigrafik birlikler ile temsil edilmektedir [23].

Çinko cevherleşmesi tümü ile metakırıntılılardan oluşan Emirgazi Grubu ve Değirmentaş formasyonu içerisinde yer almaktadır. Grup, Prekambriyen yaşlı metavolkanit arakatkılar ile yeniden kristallenmiş rekristalize kireçtaş1dolomitlerin yoğunlaştığı Kozan formasyonu ve Alt Kambriyen yaşlı kuvarsit içerikli Koçyazı formasyonu olarak ikiye ayrılmaktadır. Üst zonlarda grup ile uyumlu Orta Kambriyen yaşlı Değirmentaş formasyonu bulunmaktadır. Formasyon kireçtaşı, dolomit, stratomolitli kireçtaşı birimleri ile karakteristiktir.

Çinko cevherleşmesi üst zonlarda Değirmentaş formasyon bünyesinde yarı düzenli geometrik boyutlarda gözlenilmektedir. Bölgeye ait jeoloji haritası Şekil 1'de verilmiştir.

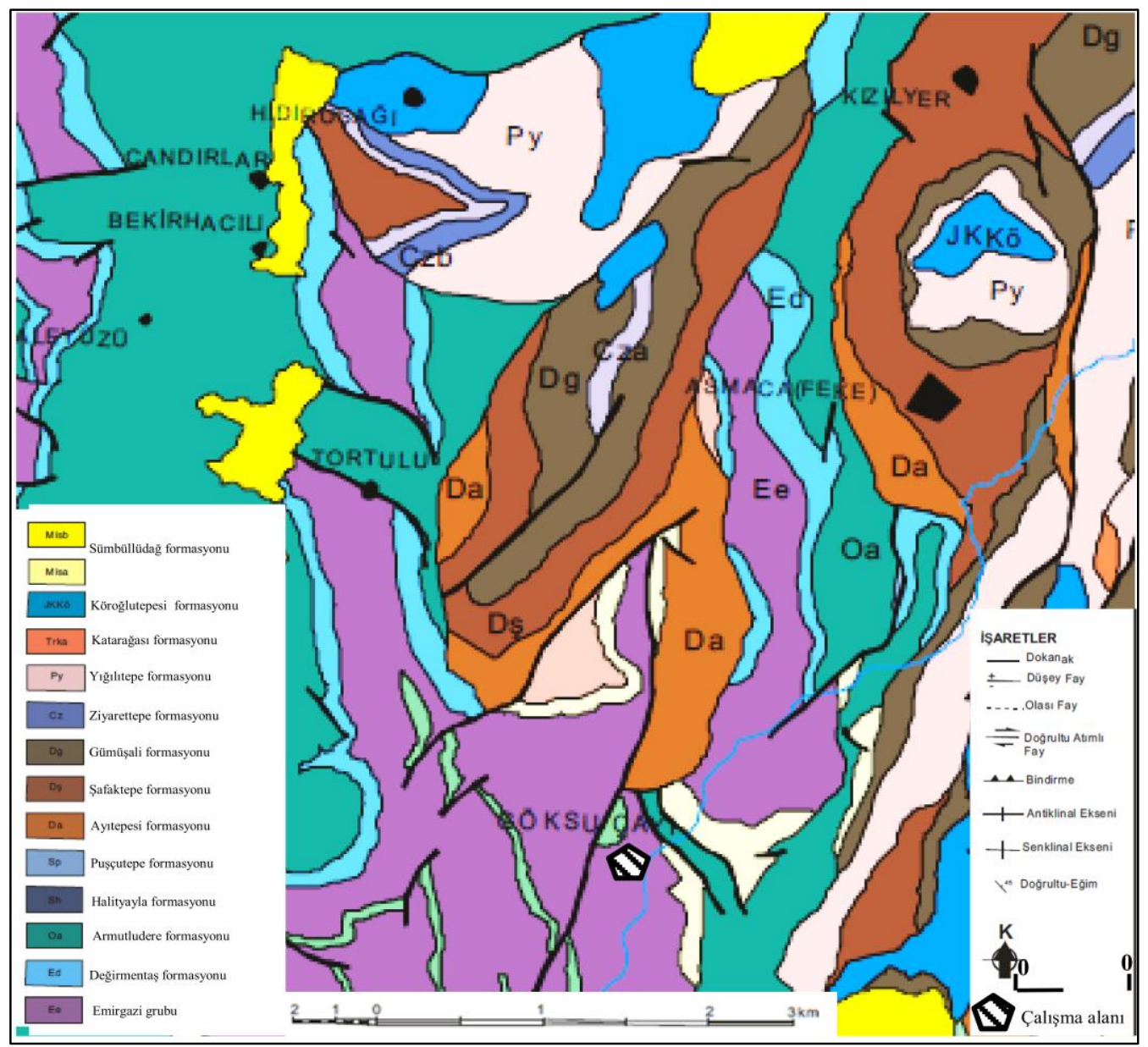

Şekil 1. Çalışma alanı jeoloji haritası [24]

\section{MATERYAL VE METOT}

Bu çalışma kapsamında 10 adet cevher örneği (C1C10) ve 10 adet kayaç örneği (K1-K10) üzerinde kimyasal ve mineralojik analizler yapılmıștır. Cevher örnekleri stok alanı, yeraltı işletmesi içesinde cevher damarlarından alınmıştır. Kayaç örnekleri ise yeraltı cevher dokanaklarından ve yüzeyden elde edilmiştir (Şekil 2). 

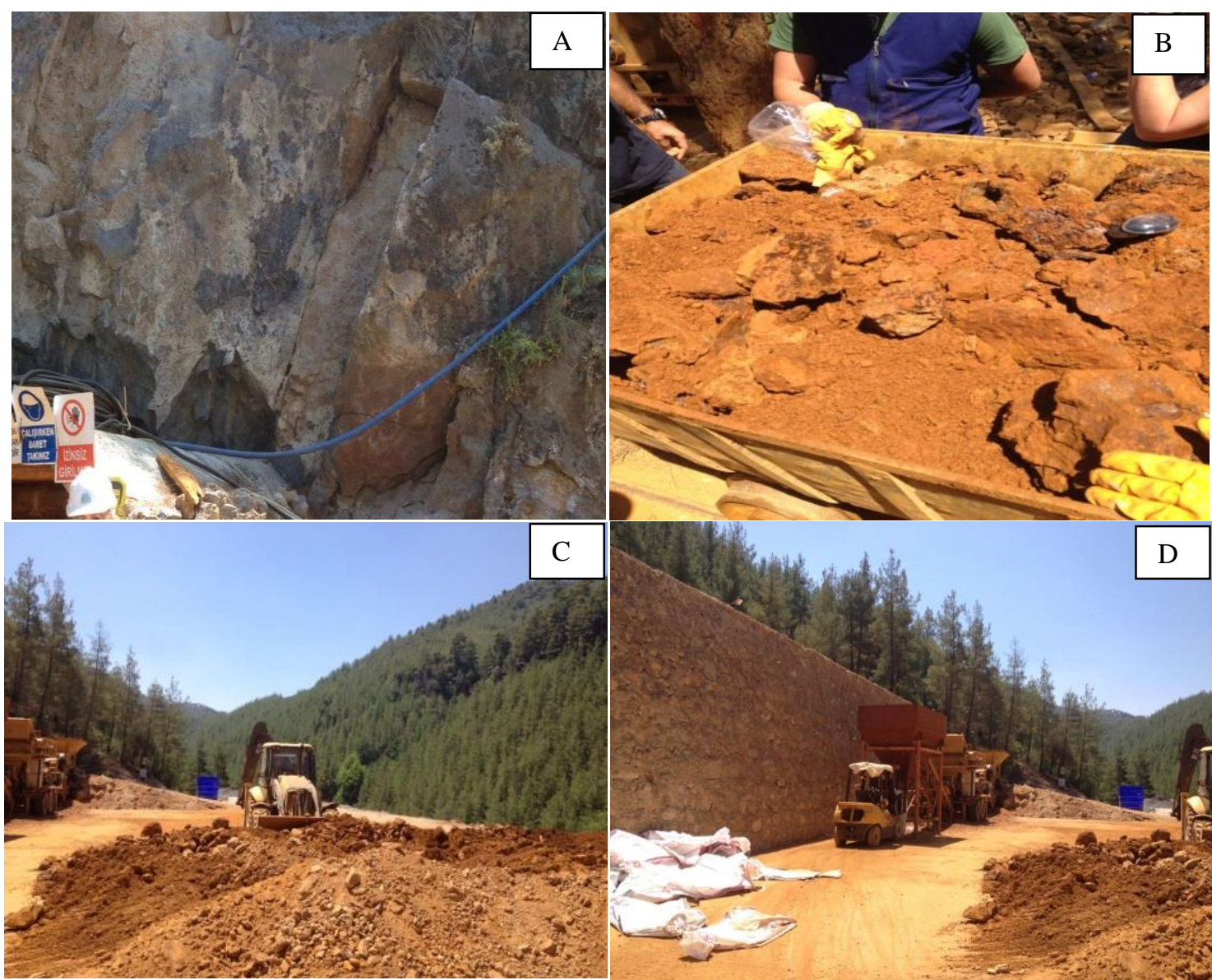

Şekil 2. A) Yankayaç (Emirgazi fm. ait kireçtaşı), B) Yeraltı galerisinden çıkan cevher ve yankayaç örnekleri, C) Cevher ve yankayaçların galeri ağzı biriktirildiği alan, D) Stok alanı genel görünümü

Cevher ve kayaç numunelerinin parajenezleri stereo ve binoküler mikroskop yardımıyla ortaya çıkarılmıştır. Ç.Ü. Maden Mühendisliği laboratuvarında çamur $\mathrm{pH}$ analizleri yapılmıştır. Ç.Ü. Merkezi Laboratuvarında X-Ișını Kırınım yöntemi (XRD) mineral analiz sonuçları $2 \varnothing 5-85^{\circ}$ aralığında PANalytical marka XRD kullanılarak elde edilmiştir. MTA laboratuvarlarında toplam S değerleri ve Thermo ARL marka XRF cihazı kullanılarak \% oksit değerler tespit edilmiştir. Asit-Baz Muhasebe (ABM) testleri kapsamında ilk adımda Asit Üretim Potansiyeli ve Nötürleştirme Potansiyeli belirlenmiștir. Fışırdama testinde $40 \mathrm{ml}$ asit miktarı ve $0,5 \mathrm{M}$ asit şiddeti uygulanmışıtır. Fışırdama testi sonrasında Nötürleștirme

potansiyeli değerleri için laboratuvarda bir dizi işlem sonucunda numunelere muamele edilen miktardaki asit şiddetinde $\mathrm{NaOH}$ çözeltisi eklenerek pH 7 oluncaya kadar işlem devam ettirilmiş ve aritmetiksel nötürleştirme potansiyelleri formül yardımı ile hesaplanmıştır.

Diğer bir parametre olan macun $\mathrm{pH}$ deneyleri meteryalin nötürleştirme kapasitesi hakkında bilgi vermektedir. Numunenin asiditesini-alkalinitesini tayin etmekte kullanılan görece hızlı, basit bir yöntemdir. Numune su ile karıştırılıp, belirli bir süre bekletildikten sonra pH'ları ölçülmüştür. Çamur pH'1 4'ün altında olan kayaçlar asit toksik kabul edilmekte ve $\% 0,5$ 'ten fazla sülfür içeren kayaçlar kayda değer potansiyel asit 
üretebilmektedir [16]. Çözeltinin pH'ının kullanılan saf suyun pH'ından büyük olması gerekmektedir. Deneylerde kullanılan saf su pH'1 5,7-6,0 değer aralığındadır.

\section{BULGULAR VE TARTIŞMA}

\subsection{Yan Kayaç ve Cevherli Örneklerin Jeokimyası}

Araziden alınan 10 adet kayaç örneği ve yeraltı maden işletmesinden alınan 10 adet cevher örneklerinin mineralojik ve kimyasal analizleri sonucu yan kayaç kalsit-dolomit mineral determinasyonu ve fosil içeriğine göre biyomikritik kireçtaşı olarak isimlendirilmiştir.

Yan kayaçlarda gerçekleştirilen ana oksit kimyasal analiz sonuçları Çizelge 1'de verilmiştir. K, V, Ba, $\mathrm{Bi}, \mathrm{Cd}, \mathrm{Co}, \mathrm{Cr}, \mathrm{Cu}, \mathrm{Ti}, \mathrm{Y}, \mathrm{Na}, \mathrm{Ni}, \mathrm{P}, \mathrm{Pb}, \mathrm{Rb}, \mathrm{Zr}$, Sn, Sr, Mo, F değerleri tayin sınırı altında olması sebebi ile Çizelge 1'de gösterilmemiştir. Yan kayaç örneklerinin (ortalama >\%1) ana oksit içerikleri değerlendirildiğinde $\mathrm{CaO}$ : \%48,95-52,71, MgO: \%1,94-3,72, $\mathrm{Fe}_{2} \mathrm{O}_{3}$ : \%0,90-2,10 değerler sunmaktadır. $\mathrm{Fe}_{2} \mathrm{O}_{3}$ değerleri $\mathrm{K} 3$ örneğinde düşük olup diğer örneklerde $\% 1$ 'in üstündedir.

Çizelge 1. Kayaçlara ait majör oksit (\%) kimyasal analiz sonuçları

\begin{tabular}{|c|c|c|c|c|c|c|c|c|c|c|}
\hline $\begin{array}{c}\text { Oksit } \\
\text { \% ağ. }\end{array}$ & $\mathrm{K} 1$ & $\mathrm{~K} 2$ & $\mathrm{~K} 3$ & $\mathrm{~K} 4$ & $\mathrm{~K} 5$ & $\mathrm{~K} 6$ & $\mathrm{~K} 7$ & $\mathrm{~K} 8$ & $\mathrm{~K} 9$ & $\mathrm{~K} 10$ \\
\hline $\mathrm{CaO}$ & 52,65 & 52,35 & 52,71 & 51,89 & 52,35 & 49,58 & 50,85 & 52,64 & 52,36 & 48,95 \\
\hline $\mathrm{MgO}$ & 2,17 & 2,41 & 2,98 & 2,01 & 3,01 & 3,54 & 3,72 & 2,21 & 1,94 & 3,65 \\
\hline $\mathrm{Al}_{2} \mathrm{O}_{3}$ & 0,25 & 0,53 & 0,35 & 0,83 & 0,27 & 0,72 & 0,95 & 0,27 & 0,21 & 0,75 \\
\hline $\mathrm{SiO}_{2}$ & 0,71 & 0,32 & 0,80 & 0,76 & 0,68 & 0,85 & 0,71 & 0,70 & 0,50 & 0,65 \\
\hline $\mathrm{MnO}$ & 0,15 & 0,09 & 0,12 & 0,14 & 0,17 & 0,15 & 0,25 & 0,21 & 0,12 & 0,15 \\
\hline $\mathrm{Fe}_{2} \mathrm{O}_{3}$ & 1,84 & 1,51 & 0,90 & 1,32 & 1,65 & 1,58 & 2,03 & 1,84 & 1,74 & 2,10 \\
\hline $\mathrm{ZnO}$ & 1,08 & 0,90 & 0,31 & 0,73 & 0,92 & 0,33 & 0,70 & 0,11 & 0,42 & 0,23 \\
\hline $\mathrm{SO}_{3}$ & $<0,01$ & 0,3 & $<0,01$ & 0,1 & $<0,01$ & $<0,01$ & $<0,01$ & $<0,01$ & $<0,01$ & 0,2 \\
\hline Toplam & 58,85 & 58,41 & 58,17 & 57,78 & 59,05 & 56,75 & 59,21 & 57,98 & 57,29 & 56,68 \\
\hline *A.K. & 40,25 & 40,13 & 40,91 & 39,87 & 40,15 & 39,87 & 39,85 & 41,65 & 41,96 & 40,23 \\
\hline
\end{tabular}

A.K.: Ateşte kayıp

$\mathrm{SO}_{3}$ değeri ise $0,3-<0,01$ değer aralığındadır. $\mathrm{Bu}$ sonuç kayaçta sülfatik kükürt oranının düşük olmasının bir göstergesidir. Kayaç numunelerinin kızdırma kayıpları ve mineralojik incelemelere dayanan $\mathrm{CaCO}_{3}-\mathrm{CaMg}\left(\mathrm{CO}_{3}\right)_{2}$ içerikleri esas alınarak (Çizelge 1'de görülen ateşte kayıp değerlerinin başlıca karbonat minerallerinden kaynaklandığı varsayılmıştır) toplam karbonat miktarları Çizelge 2'de verilmiştir.

Asit kaya/maden drenajı kestiriminde, potansiyel asiditenin saptanması, kükürt $(\mathrm{S})$ analizine dayalıdır. $S$ ise çeşitli minerallerin bünyesinde sülfit, sülfat ve organik form gibi farklı biçimlerde bulunabilir. MTA laboratuvarlarında yaptırılan kükürt analiz sonuçları Çizelge 3'de verilmiştir.
Örneklerde elde edilen kimyasal sonuçlarına göre sülfit $\left(\mathrm{SO}_{3}: 0,3-<0,01\right)$ ve organik kükürt oran1 göz ardı edilecek miktarlarda olduğu için bulunan oran piritik kükürt olarak değerlendirilmiştir. Kayaç içerisinde kükürt değerleri $(\% \mathrm{~S}) \quad 0,04-0,12$ aralığında tespit edilmiştir. Karbonat kayaç bünyesi için bu değer yüksek bir oranı ifade etmektedir. Cevher kimyasal analiz sonuçları toplam 10 adet örnek üzerinde yapılan XRF sonuçları olarak Çizelge 3 oluşturulmuştur. Çizelgeye göre $\mathrm{CaO}$ : \%9,97-18,36, MgO:\%0,010,09, $\mathrm{Fe}_{2} \mathrm{O}_{3}$ : \%25,40-55,60 değerler sunmaktadır. Cevherlerde $\mathrm{Fe}_{2} \mathrm{O}_{3}$ oranı \%25,40-55,60 aralığında yüksek bir değerdedir. Kükürt değerleri ise \%0,13-0,39 aralığında saptanmıştır. 
Adana-Feke Yöresi Yeraltı Çinko Cevherleşmesinin Asit Maden Drenajı Oluşumuna Yönelik Kestirimlerinin Araştırılması

Çizelge 2. Kayaçta toplam karbonat değerleri

\begin{tabular}{|c|c|c|c|c|}
\hline \multirow{2}{*}{$\begin{array}{c}\text { Numune } \\
\text { No }\end{array}$} & Kizdirma Kayılar1 & $\mathrm{X}_{\mathrm{CaCO} 3}$ & $\mathrm{X}_{\mathrm{CaMg}(\mathrm{CO}) 2}$ & Toplam Karbonat \\
\cline { 2 - 5 } & $(\%)\left(1000^{\circ} \mathrm{C}^{\prime}\right.$ de 2 Saat $)$ & $(\%)$ & $(\%)$ & $(\%)$ \\
\hline K1 & 40,25 & 93,87 & 4 & 98,41 \\
\hline K2 & 40,13 & 93,34 & 5 & 98,38 \\
\hline K3 & 40,91 & 93,98 & 6 & 98,60 \\
\hline K4 & 39,87 & 92,52 & 4 & 97,54 \\
\hline K5 & 40,15 & 93,34 & 7 & 95,80 \\
\hline K6 & 39,87 & 88,40 & 7 & 97,67 \\
\hline K7 & 39,85 & 90,67 & 4 & 97,86 \\
\hline K8 & 41,65 & 93,86 & 4 & 97,41 \\
\hline K9 & 41,96 & 93,36 & 7 & 94,28 \\
\hline K10 & 40,23 & 87,28 & 5 & \\
\hline
\end{tabular}

Çizelge 3. Cevherlere ait majör oksit (\%) kimyasal analiz sonuçları

\begin{tabular}{|c|c|c|c|c|c|c|c|c|c|c|}
\hline $\begin{array}{c}\text { Oksit } \\
(\% \text { ağ, })\end{array}$ & $\mathrm{C} 1$ & $\mathrm{C} 2$ & C3 & $\mathrm{C} 4$ & $\mathrm{C} 5$ & C6 & $\mathrm{C} 7$ & $\mathrm{C} 8$ & C9 & $\mathrm{C} 10$ \\
\hline $\mathrm{CaO}$ & 13,44 & 12,99 & 9,97 & 11,32 & 12,99 & 10,98 & 13,63 & 18,36 & 13,85 & 12,46 \\
\hline $\mathrm{MgO}$ & 0,09 & 0,05 & 0,04 & 0,09 & 0,03 & 0,07 & 0,05 & 0,04 & 0,02 & 0,01 \\
\hline $\mathrm{Al}_{2} \mathrm{O}_{3}$ & 0,98 & 0,87 & 7,01 & 1,08 & 0,87 & 1,08 & 0,95 & 0,97 & 0,52 & 0,42 \\
\hline $\mathrm{SiO}_{2}$ & 3,50 & 4,70 & 9,71 & 5,31 & 3,82 & 8,10 & 5,30 & 7,90 & 2,98 & 2,41 \\
\hline $\mathrm{MnO}$ & 0,09 & 0,41 & 0,21 & 0,05 & 0,05 & 0,02 & 0,08 & 0,06 & 0,21 & 0,16 \\
\hline $\mathrm{Fe}_{2} \mathrm{O}_{3}$ & 25,40 & 48,41 & 55,60 & 32,32 & 27,36 & 51,62 & 38,69 & 41,98 & 27,91 & 36,41 \\
\hline $\mathrm{ZnO}$ & 43,70 & 22,20 & 6,96 & 37,30 & 41,60 & 10,65 & 27,63 & 15,96 & 33,56 & 35,51 \\
\hline $\mathrm{SO}_{3}$ & 0,09 & 0,07 & 0,21 & 0,25 & 0,08 & 0,08 & 0,10 & 0,16 & 0,08 & 0,09 \\
\hline $\mathrm{PbO}$ & 2,95 & 2,18 & 3,15 & 2,80 & 3,12 & 2,69 & 3,10 & 2,85 & 2,10 & 2,10 \\
\hline Toplam & 90,24 & 91,88 & 92,86 & 90,52 & 89,92 & 85,29 & 89,53 & 88,28 & 81,23 & 89,57 \\
\hline *A.K. & 9,32 & 7,91 & 6,95 & 8,85 & $\mathbf{9 , 8 1}$ & 8,36 & 8,65 & 10,23 & 10,32 & 9,12 \\
\hline
\end{tabular}

A.K.: Ateşte kayıp

Cevherleşmedeki sülfid oluşumları, hidrotermal fazlardaki hareketli elementlerin kayaçlardaki değişimleri sonucu ortaya çıkabilmektedir. Demir sülfid minerallerinin çcözünme yetenekleri oldukça fazladır. Dolayısıyla demir sülfidler çözünürken $\mathrm{Ag}, \mathrm{Cu}, \mathrm{Hg}, \mathrm{Pb}, \mathrm{Cd}, \mathrm{Mo}, \mathrm{Ni}, \mathrm{Co}, \mathrm{Zn}$ ve $\mathrm{W}$ elementlerinin diğer bileşiklerini sülfide dönüştürerek çöktürebilmektedir [25]. Bu kimyasal olay sonucu ise cevher parajenizinde sülfürlü minerallerin önemi artmaktadır.

\subsection{Yan Kayac ve Cevherli Örneklerin Petrografik-Mineralojik Değerlendirmeleri}

Yan kayaç ve cevher örneklerinin parlak kesit ve , ince kesit mikroskop incelemeleri sonucu mineral parajenezleri ortaya konmuş ve örneklere ait XRD patern çekimleri gerçekleştirilmiştir.

Kayaç açık gri renkli rekristalize özelliktedir. Kayaç içeriği \%85-90 oranında kalsit $\left(\mathrm{CaCO}_{3}\right)$, \%2-3 oranında dolomit $\mathrm{CaMg}\left(\mathrm{CO}_{3}\right)_{2}$, \%7-10 
oranında ise fosil kavkılarından oluşmaktadır. Kalsit kristalleri çoğunlukla mikritik boyutta gözlenmiştir. Demir boyama şeklinde kılcal boşluklarda ve nadir olarak opak mineral şeklinde saptanmıştır. Kayaç ince kesit ve XRD görüntüleri Şekil 3'de verilmiştir.

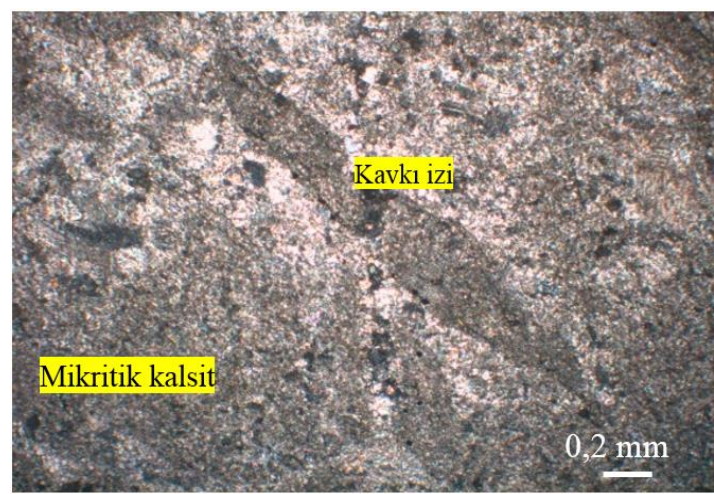

(A)

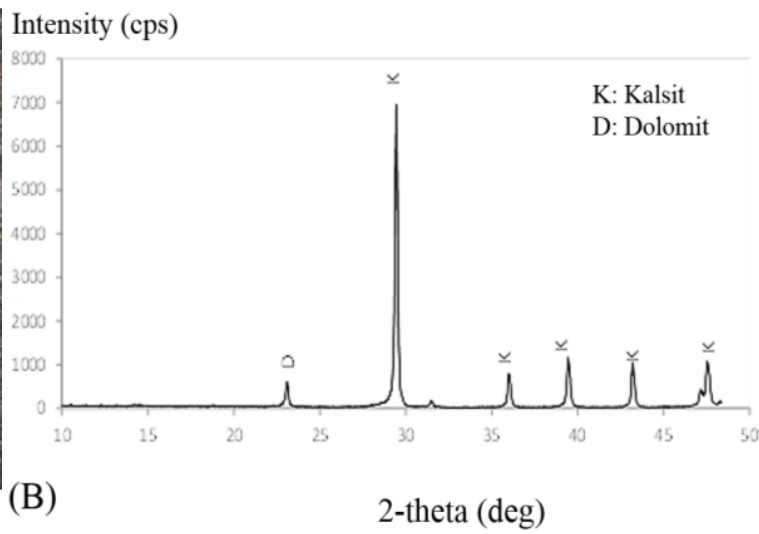

2-theta (deg)

Şekil 3. İnce kesit görüntüsünde kalsit, dolomit (A) ve XRD patern diyagramı (B)

Cevher mineralojisi tespiti parlak kesit, XRD, lup ve arazi gözlemleri sonucu olmuştur. Cevherleşmede karbonat, oksit, hidroksil mineralleri ve ikincil karbonat ve oksitli cevher mineralleri bulunmaktadır. Sülfür mineralleri arasında asit üretmede as1l mineral olan pirit $\left(\mathrm{FeS}_{2}\right)$ az oranda gözlenmiştir. Smitsonit cevheri $\left(\mathrm{ZnCO}_{3}\right)$, kireçtaşları içerisinde oksidasyon zonunda mercek ve dissemine (saçınımlı) olarak bulunmaktadır. Mevcut faylanmalara bağlı olarak, fay zonlarında ikincil cevherleşmeler gelişmiştir (hidrozinkit, zinkit, götit). Çinko cevher ana minerali smitsonit $\left(\mathrm{ZnCO}_{3}\right)$ olup hematit $\left(\mathrm{Fe}_{2} \mathrm{O}_{3}\right)$, götit $\left(\mathrm{HFeO}_{2}-\mathrm{FeO}(\mathrm{OH})\right) \quad$ hidrozinkit $\left(\mathrm{Zn}_{5}\left(\mathrm{CO}_{3}\right)_{2}(\mathrm{OH})_{6}\right)$, zinkit $(\mathrm{ZnO})$ ve limonit $\left(\mathrm{FeO}(\mathrm{OH}) \cdot \mathrm{nH}_{2} \mathrm{O}\right) \quad$ parajenezdeki diğer metaliklerdir. Gang mineralleri; kalsit $\left(\mathrm{CaCO}_{3}\right)$ ve kuvars $\left(\mathrm{SiO}_{2}\right)$ dir. Oksidasyon zonunda bulunan hematit, limonit ve götit mineralleri cevherde demir oranını yükseltmektedir. Cevherde lup ile pirit minerali yok denecek kadar az gözlenmiştir. Cevher mineralojisini yansitan parlak kesit ve XRD patern görünüm Şekil 4'de verilmiştir.

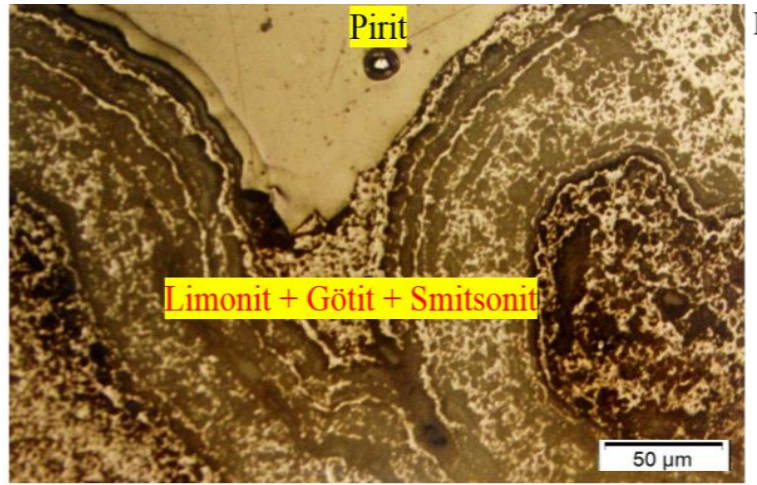

(A)

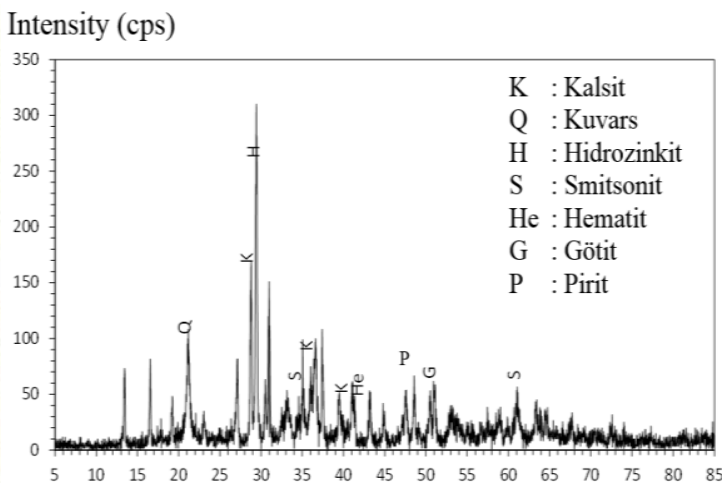

(B) 2-theta (deg)

Şekil 4. Parlak kesit görüntüsünde cevher mineralleri (A) ve XRD patern diyagramı (B) 


\section{ASITT-BAZ MUHASEBE SONUÇLARI (ABM)}

\section{1. Çamur pH Değerlendirmesi}

Çukurova Üniversitesi Maden Mühendisliği Bölüm laboratuvarında yapılan ve önceki bölümde verilen bir dizi işlemler sonucu kayaç ve cevherli örneklerin 10 adet cevherde ve kayaçta Çamur $\mathrm{pH}$ değerleri elde edilmiştir (Çizelge 5). Deneylerde kullanılan saf suyun pH'1 5,7-6,0 aralığındadır. Çamur pH, cevherde: 5,8-7,4, kayaçta: 7,1-8,3 aralığında ölçülmüştür.

\subsection{AÜP (Asit Üretim Potansiyeli) ve NP (Nötürleştirme Potansiyeli Değer Sonuçları}

Çalışma alanından alınan karbonatlı kayaç ve çinko cevher örneklerinden elde edilen AÜP, NP, Toplam S, Çamur pH değerleri ABM yorumlama tablosunda verilmiştir (Çizelge 5). Bu tabloda NP ve AÜP değerlerinden NetNP ve NPO (Nötürleştirme Potansiyel Oranı) hesaplanmıştır. Çizelge 5'deki verilere göre çizilen AÜP-NP ve Çamur pH-NNP diyagramında değerler 'potansiyel asit üretmeyen' bölgeye düşmüştür (Şekil 5-6). Yeraltı çinko cevherleşmesinde minerallerin her ne kadar karbonatça zengin parajenezleri olsa da cevher mekanizması gereği bölgede sülfür içerikli minerallerin daha fazla görülme olasıllğı oldukça yüksektir. Gerek hammadde alım esnasında gerekse stoklanma sonucu başta pirit olmak üzere sülfürlü mineraller içerebilecek cevherin ve yan kayacın atmosferik sularla açık alanda asit üretme potansiyeli mevcuttur.

Çizelge 5. Numunelerin Asit/Baz muhasebe tablosu

\begin{tabular}{|c|c|c|c|c|c|c|c|}
\hline Numune & $\begin{array}{c}\text { Fişırdama hiz1 } \\
\text { (0=Yok, 1=Hafif, } \\
\text { 2=Orta, } \\
\text { 3=Kuvvetli) }\end{array}$ & $\% \mathrm{~S}$ & Çamur pH & $\mathrm{AÜP}$ & $\begin{array}{c}\mathrm{NP} \\
\begin{array}{c}\mathrm{NP}(\mathrm{kg} / \mathrm{ton}) \\
\mathrm{kgCaCO}_{3} / \mathrm{ton}\end{array}\end{array}$ & $\begin{array}{c}\text { Net NP } \\
(\mathrm{NP}-\mathrm{AÜP}) \\
\mathrm{kgCaCO}_{3} / \text { ton }\end{array}$ & $\begin{array}{c}\text { NPO } \\
(\mathrm{NP} / \mathrm{AÜP}) \\
\mathrm{kgCaCO}_{3} / \text { ton }\end{array}$ \\
\hline C1 & 2 & 0,17 & 6,5 & 10,63 & 120,33 & 109,70 & 11,32 \\
\hline C2 & 2 & 0,27 & 6,2 & 16,88 & 116,09 & 99,21 & 6,88 \\
\hline C3 & 2 & 0,25 & 6,1 & 15,63 & 89,11 & 73,48 & 5,70 \\
\hline C4 & 2 & 0,27 & 6,2 & 16,88 & 101,43 & 84,55 & 6,01 \\
\hline C5 & 3 & 0,13 & 7,4 & 8,13 & 115,98 & 107,85 & 14,27 \\
\hline C6 & 2 & 0,36 & 5,8 & 22,50 & 98,28 & 75,78 & 4,37 \\
\hline C7 & 2 & 0,39 & 5,8 & 24,38 & 121,79 & 97,42 & 5,00 \\
\hline C8 & 2 & 0,29 & 6,1 & 18,13 & 163,91 & 145,78 & 9,04 \\
\hline C9 & 2 & 0,28 & 6,3 & 17,50 & 123,59 & 106,09 & 7,06 \\
\hline C10 & 2 & 0,37 & 5,9 & 23,13 & 111,14 & 88,01 & 4,81 \\
\hline & 3 & 0,08 & 7,8 & 5,00 & 480,22 & 475,22 & 96,04 \\
\hline K1 & 3 & 0,12 & 6,8 & 7,50 & 480,36 & 472,86 & 64,05 \\
\hline K2 & 3 & 0,11 & 7,2 & 6,88 & 483,47 & 476,59 & 70,32 \\
\hline K3 & 3 & 0,09 & 7,6 & 5,63 & 479,10 & 473,47 & 85,17 \\
\hline K4 & 3 & 0,09 & 7,6 & 5,63 & 478,10 & 472,47 & 84,99 \\
\hline K5 & 3 & 0,05 & 8,1 & 3,13 & 462,08 & 458,95 & 147,86 \\
\hline K6 & 3 & 0,04 & 8,3 & 2,50 & 472,31 & 469,81 & 188,92 \\
\hline K7 & 3 & 0,07 & 7,9 & 4,38 & 480,13 & 475,76 & 109,74 \\
\hline K8 & 3 & 0,10 & 7,1 & 6,25 & 477,79 & 471,54 & 76,45 \\
\hline K9 & 3 & 0,07 & 7,9 & 4,38 & 455,37 & 450,99 & 104,08 \\
\hline K10 & & & & & & \\
\hline
\end{tabular}




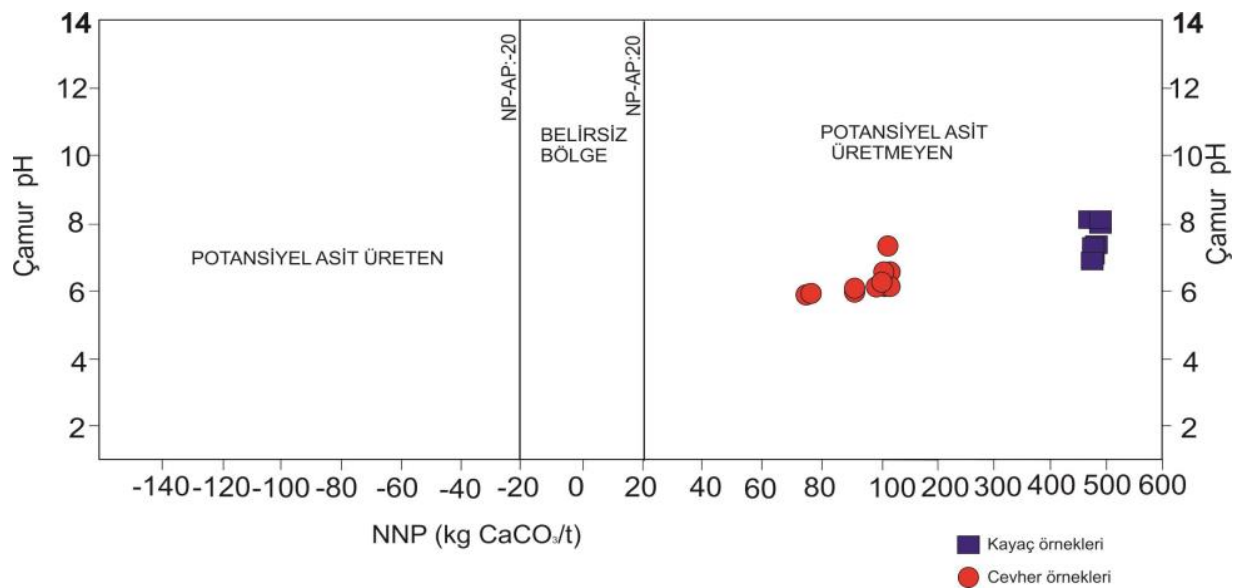

Şekil 5. Numunelerin NNP- Çamur pH diyagramyorumu [26]

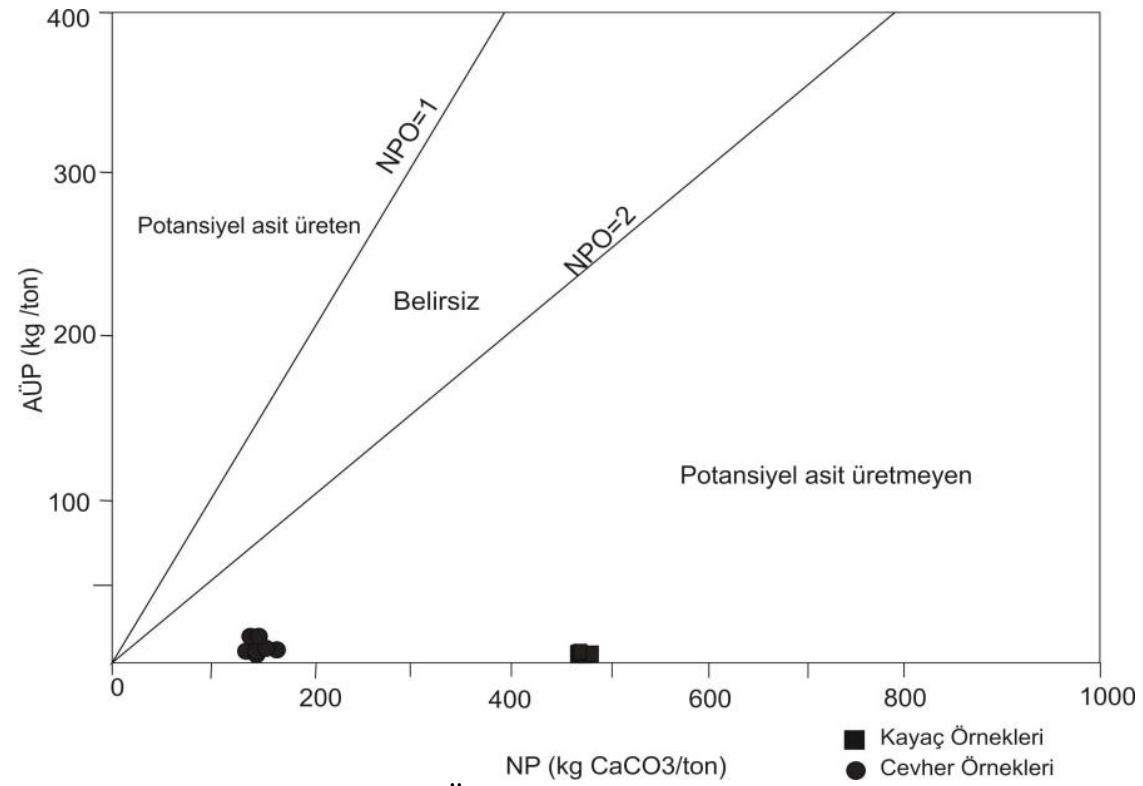

Şekil 6. Numunelerin AÜP- NP diyagramındaki konumları [27-29]

\section{SONUÇLAR}

Bu çalışmada M35-b4 paftası sınırları içerisinde bulunan Adana ili Feke ilçesine $5 \mathrm{~km}$ uzaklıkta bulunan yeraltı işletmesine ait çinko cevherleşmesinin asit üretme potansiyeli araştırılmıştır. Bulgulara göre;

* Cevherleşme çoğunlukla Değirmentaş formasyonu ile temsil edilen karbonatlı seri içerisinde, yarı düzenli geometrik boyutlarda damar ve faylanmalara bağlı olarak oluşmuştur.

Cevher ve kayaç analizlerine göre;

* Yan kayaç örneklerinin ana ana oksit içerikleri ve mineral içeriği değerlendirilmeleri sonucu kayacın biyomikritik kireçtaşı olduğu tespit edilmiştir. 
* Kayaç içerisinde kükürt değerleri (\% S) 0,040.12 aralığındadır. Ölçülen çamur $\mathrm{pH}$ değeri ise 7,1-8,3 arasında saptanmışır.

* Cevher; Smitsonit $\left(\mathrm{ZnCO}_{3}\right)$, hidrozinkit $\left(\mathrm{Zn}_{5}\left(\mathrm{CO}_{3}\right)_{2}(\mathrm{OH})_{6}\right)$, zinkit ( $\left.\mathrm{ZnO}\right)$, hematit $\left(\mathrm{Fe}_{2} \mathrm{O}_{3}\right)$, götit $\left(\mathrm{HFeO}_{2^{-}} \mathrm{FeO}(\mathrm{OH})\right)$, limonit $\left(\mathrm{FeO}(\mathrm{OH}) \cdot \mathrm{nH}_{2} \mathrm{O}\right)$ ve az oranda pirit $\left(\mathrm{FeS}_{2}\right)$ minerallerinden oluşmaktadır. Kükürt değerleri $\% 0.13-0.39$ ve çamur $\mathrm{pH} ; 5,7-7,4$, aralı̆̆ında tespit edilmiştir.

* AÜP, NP, NetNP, NPO değerlerine (ABH Muhasebe tablosu) göre çizilen NNP-Macun $\mathrm{pH}$ ile AÜP-NP diyagram yorumunda tüm kayaç ve cevher örnekleri 'Potansiyel asit üretmeyen' bölgeye düşmüştür.

* Price ve arkadaşları, (1997), Soregaroli ve Lawrence (1998)'e göre 'NPO>4 asit üretmez (yeterli nötürleştirme kapasitesine sahip)' değerlendirme sonucu yapılan çalışmada kayaçta NPO değeri tüm örneklerde sağlanırken, cevherde 4,37-14,27 değerleri kritik olarak algılanmalıdır [30-31]. Cevher mekanizması gereği üst zonlarda oksidasyondan kaynaklanan karbonatlı cevher minerallerinin ana parajenez olması ve ileriki yıllarda sülfürlü zonlara geçiş ve özellikle pirit minerallerinin cevher eşlik edeceği öngörülmeli ve madencilik faaliyetleri sırasında gerekli önlemler alınmalıdır. Özellikle stoklama alanlarının çevreye kolayca sızıntı oluşturmaması için "Konuyla İlgili Ülkemizdeki Yasa ve Yönetmelikler" doğrultusunda hazırlanması "Bu Yasa ve Yönetmeliklere" uyulması zorunludur.

\section{KAYNAKLAR}

1. Yörükoğlu, A., Karadeniz, M., 2003. Asit Maden Drenaj1 Kestirim Yöntemlerinin Karşılaştırılması, Türkiye 18 Uluslararası Madencilik Kongresi ve Sergisi- IMCET2003 \& 2003, ISBN 975-395-606-1.

2. Paine, P.J., 1987. An Historic and Geographical Overview of Acid Drainage, In Proceedings: Acid Mine Drainage Seminar/Workshop, Conservation and
Protection Environment, Ontario, Canada, $1-45$.

3. Skousen, J.G., 1996. Acid Mine Drainage Control and Treatment (Compiled by J.G. Skousen and P.F. Ziemkiewicz), W.V. Univ. and N.M.L.R.C. 9-12.

4. Balcı, Ç.N., Gül, S., Kılıç, M.M., Karagüler, N.G., Sarı, E., Sönmez, M.Ş., 2014. Balya (Balıkesir) $\mathrm{Pb}-\mathrm{Zn}$ Madeni Atık Sahasının Biyojeokimyas1 ve Asidik Maden Drenaj1 Oluşumuna Etkileri, Türkiye Jeoloji Bülteni, 57(3), 1-24.

5. Gray, N.F., 1997. Environmental Impack and Remediation of Acid Mine Drainage: A Management Problem, Environmental Geology, 30, (1/2), March, 62-71.

6. Rötting, T.S., Caraballo, M.A., Serrano, J.A., Ayora, C., Carrera, J., 2008. Field Application of Calcite Dispersed Alkaline Substrate (Calcite-DAS) for Passive Treatment of Acid Mine Drainage with High Al and Metal Concentrations. Applied Geochemistry, 23, 1660-1674.

7. Caraballo, M.A., Rötting T.S., Macías F., Nieto J.M., Ayora, C., 2009. Field Multi-Step Limestone and Mgo Passive System to Treat Acid Mine Drainage with High Metal Concentrations. Applied Geochemistry, 24, 2301-2311.

8. Delibalta, M.S., Uzal, N., Lermi, A., 2016. Acid Mine Drainage and Rehabilitation in Ilgin Lignite Mines Lakes. Nigde University Journal of Engineering Sciences 5(1), 73-82.

9. Berghorn, G.H., Hunzeker G.R., 2001. Passive Treatment Alternatives for Remediating Abandoned-mine Drainage. Remediation 11, 111-127.

10. Marchand L., Mench M., Jacob D.L., Otte M.L., 2010. Metal and Metalloid Removal in Constructed Wetlands, with Emphasis on the Importance of Plants and Standardized Measurements: A Review. Environmental Pollution, 158, 3447-3461.

11. Lottermoser B.G., Ashley P.M., 2011. Trace Element Uptake by Eleocharis Equisetina (Spike Rush) in an Abandoned Acid Mine Tailings Pond, Northeastern Australia: Implications for Land and Water Reclamation 
in Tropical Regions. Environmental Pollution, 159, 3028-3035.

12. Akaryalı, E., Gücer, M.A., Alemdağ, S., 2018. Atık Barajı Rezervuarı ve Cevher Stok Alanlarında Asit Maden Drenajı (AMD) Oluşumunun Değerlendirilmesi: Gümüşhane Örneği, Artvin Çoruh Üniversitesi, Doğal Afetler ve Çevre Dergisi, 4(2), 192-209, Doi:10.21324/dacd.415259.

13. Alemdağ S., Akayalı, E., Gücer, M.A., 2020a. Flotasyon Tesis Atıklarının Asit Üretme Potansiyeli ve Kirliliğin Önlenmesi, Gümüşhane, KD Türkiye, Yerbilimleri, 41(1) 56-85, DOI: 10.17824.

14. Alemdağ, S., Akaryalı, E., Gücer, M.A., 2020b. Prediction of Mine Drainage Generation Potential and the Prevention Method in the Gümüşköy (Kütahya) Mineralization Area, NW-Turkey. Journal of Mountain Science, 17(10), 2387-2404.

15. Gücer, M.A., Alemdağ, S., Akaryalı, E., 2020. Assessment of Acid Mine Drainage Formation Using Geochemical and Static Tests in Mutki (Bitlis, SE Turkey) Mineralization Area. Turkish Journal of Earth Sciences, 29(7), 1189-1210.

16. Miller, S.D., 1996. Advances in Acid Mine Drainage: Prediction and Implication for Risk Management. Proceeding of the $3^{\text {rd }}$ International and $21^{\text {st }}$ Annual Minerals Council of Australia Environmental Workshop. 149-157.

17. Morin, K.A., Hutt, N.M., 1997. Environmental Geochemistry of Minesite Drainage; Practical Theory and Case Studies. Canada, 333.

18. White, W.W.III., Lapokko, K.A., Cox, R.L., 1999. Static Test Methods Most Commonly Used to Predict Acid Mine Drainage: Practical, Guidelines for Use and Interpratation. 325-338.

19. Paktunç, A.D., 1999. Minerological Constrains on the Determination of Neutralization Potential and Prediction of Acid Mine Drainage. Environmental Geology. 38, 82-84.

20. Jambor, J.L., Dutrizac, J.E., Chen, T.T., 2000. Statik Testlerde Belirli Minerallerin Nötralizasyon Potansiyeline Katkıları. 551-565. In Proc. $5^{\text {th }}$ Int. Conf. Acid Rock Drainage, Denver. 21-24 Cilt. 1. Soc. Madencilik Metal. Keşfedin, Littleton, CO.
21. Jambor, J.L., Dutrizac. J.E., 2002. Asit Drenajının Statik Test Tahminlerinde Partikül Boyutunun Nötralizasyon Potansiyeli Üzerindeki Etkisi, 651- 663.

22. Weber, P.A., Hughesu, J.B., Conner, L.B., Lindsay, P., Smart, R.C., 2006. Shortterm Acid Rock Drainage Characteristics Determined by Paste $\mathrm{Ph}$ and Kinetic Nag Testing: Cypress Prospect, New Zealand.

23. Özgül, N., Kozlu, H., 2002. Kozan-Feke (Doğu Toroslar) Yöresinin Stratigrafisi ve Yapisal Konumu ile İlgili Bulgular, Türkiye Petrol Jeologları Derneği Bülteni, 14(1), 1-36.

24. Ayhan, A., 1988. 1/100.000 Ölçekli Açınsama Nitelikli Türkiye Jeoloji Haritaları Serisi, Kozan- J21 paftası, MTA yayınları, Ankara.

25. Ata, E., 2005. Divriği-Pınargözü (Sivas), Hekimhan (Malatya), Attepe (Kayseri) ve Feke (Adana) Demir Cevherleşmelerindeki Hematitlerin Karşılaştırmalı Jeokimyasal İncelenmesi, Çukurova Üniversitesi, Fen Bilimleri Enstitüsü, Yüksek Lisans Tezi, 95.

26. Ferguson, K.D., Morin, K.A., 1991. The Prediction of Acid Rock Drainage-Lessons from the Database. In: Proceedings of the $2^{\text {nd }}$ ICARD, vol 1-4. Montréal, QC, Canada, 83-106.

27. Sobek, A.A., Schuller, W.A., Freeman, J.R., Smith, R.M., 1978. Field and Laboratory Methods Applicable to Overburdens and Minesoils. EPA-600/2-78-054. US Govt Printing Office, Washington, DC.

28. Brodie, M.J., Broughton L, M., Robertson A., 1991. A Conceptual Rock Classification System for Waste Management and Laboratory Method for Ard Prediction from Rock Piles, Second Internetional Conference on the Abatement of Acid Drainage, Vol,3 Montreal, Quebec, September 16-18, MEND Program Ed- Quebec Mining Association, Otawa, 119-135.

29. Lapakko, K., 1992. Characterization and Static Testing of Ten Gold Mine Tailings. Proceedings America Society of Mining and Reclamation, 370-384.

30. Price, W.A., Errington, J., Koyanagi, V., 1997. Guidelines for the Prediction of Acid Rock Drainage and Metal Leaching for Mines in British Columbia: Part I. General Procedures 
Adana-Feke Yöresi Yeraltı Çinko Cevherleşmesinin Asit Maden Drenajı Oluşumuna Yönelik Kestirimlerinin Araştırılması

and Information Requirements. In: Proc, $4^{\text {th }}$ ICARD, Natural Resources Canada, Ottawa, 1, 1-14.

31. Soregaroli, B.A, Lawrence, R.W., 1998. Update on Waste Characterisation Studies. In: Proceedings Mine Design, Operations and Closure Conference, Polson, MT, USA. 